\title{
BMJ Open Increasing the value of health research in the WHO African Region beyond 2015 - reflecting on the past, celebrating the present and building the future: a bibliometric analysis
}

\author{
Olalekan A Uthman, ${ }^{1,2}$ Charles Shey Wiysonge, ${ }^{1,3}$ Martin O Ota, ${ }^{4}$ Mark Nicol, ${ }^{5}$ \\ Gregory D Hussey, ${ }^{5}$ Peter M Ndumbe, ${ }^{4}$ Bongani M Mayosi ${ }^{6}$
}

To cite: Uthman $O A$, Wiysonge CS, Ota MO, et al. Increasing the value of health research in the WHO African Region beyond 2015reflecting on the past, celebrating the present and building the future: a bibliometric analysis. BMJ Open 2015;5:e006340. doi:10.1136/bmjopen-2014006340

- Prepublication history and additional material is available. To view please visit the journal (http://dx.doi.org/ 10.1136/bmjopen-2014006340).

OAU and CSW contributed equally.

Received 11 August 2014 Revised 12 December 2014 Accepted 15 December 2014

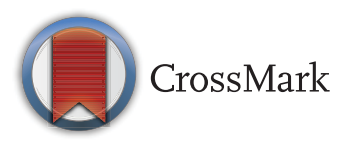

For numbered affiliations see end of article.

Correspondence to Charles Shey Wiysonge; charlesw@sun.ac.za

\section{ABSTRACT}

Objective: To assess the profile and determinants of health research productivity in Africa since the onset of the new millennium.

Design: Bibliometric analysis.

Data collection and synthesis: In November 2014, we searched PubMed for articles published between 2000 and 2014 from the WHO African Region, and obtained country-level indicators from World Bank data. We used Poisson regression to examine time trends in research publications and negative binomial regression to explore determinants of research publications.

Results: We identified 107662 publications, with a median of 727 per country (range 25-31 757). Three countries (South Africa, Nigeria and Kenya) contributed $52 \%$ of the publications. The number of publications increased from 3623 in 2000 to 12709 in 2014 (relative growth $251 \%$ ). Similarly, the per cent share of worldwide research publications per year increased from $0.7 \%$ in 2000 to $1.3 \%$ in 2014 . The trend analysis was also significant to confirm a continuous increase in health research publications from Africa, with productivity increasing by $10.3 \%$ per year $(95 \% \mathrm{Cls}$ $+10.1 \%$ to $+10.5 \%$ ). The only independent predictor of publication outputs was national gross domestic product. For every one log US\$ billion increase in gross domestic product, research publications rose by $105 \%$ : incidence rate ratio (IRR=2.05, 95\% $\mathrm{Cl} 1.39$ to 3.04 ). The association of private health expenditure with publications was only marginally significant $(\mathrm{IRR}=1.86$, $95 \%$ Cl 1.00 to 3.47 ).

Conclusions: There has been a significant improvement in health research in the WHO African Region since 2000, with some individual countries already having strong research profiles. Countries of the region should implement the WHO Strategy on Research for Health: reinforcing the research culture (organisation); focusing research on key health challenges (priorities); strengthening national health research systems (capacity); encouraging good research practice (standards); and consolidating linkages between health research and action (translation).

\section{Strengths and limitations of this study}

- To the best of our knowledge, this is the first quantitative assessment of health research publications from the WHO African Region since the start of the new millennium. The study has added value to the knowledge of health research productivity on the African continent.

- The study used negative binomial regression to explore factors associated with research publications because of greater variability than expected in the number of research publications. When such overdispersion exists, negative binomial regression employs a more robust method to fit count data than Poisson regression.

- It is a weakness of this study that we did not conduct a descriptive analysis of study types and quality. However, such a qualitative assessment was beyond the scope of the study and should be the subject of further studies on research productivity in Africa.

\section{INTRODUCTION}

In 2000, world leaders pledged to eradicate extreme poverty and improve the well-being of the world's poorest people by 2015, with 1990 as the baseline. This promise was contained in the United Nations Millennium Declaration. ${ }^{1}$ Derived from the pledge are eight time-bound goals, the Millennium Development Goals (MDGs). ${ }^{1}$ Three MDGs focus entirely on health, namely MDG-4, which targets a two-third reduction in under-5 mortality, MDG-5, which aims to reduce the maternal mortality ratio by three-quarters and MDG-6, whose targets are to halt and begin to reverse the spread of HIV and the incidence of malaria, tuberculosis and other major diseases by $2015 .^{1}$ Many countries in the WHO African Region are making progress towards the achievement of the health MDGs; however, the 
progress is not fast enough to ensure the attainment of these goals. ${ }^{2}$ Improved progress would require national decision-makers in the region to access high-quality policyrelevant health research and integrate this evidence into their health systems. ${ }^{3}$ The pre-requisite for such evidenceinformed decision-making is the strengthening of national health research systems to generate and disseminate relevant and high-quality research evidence, which can be used for policy and public health action. ${ }^{45}$

Although the MDGs are an overarching development framework and increasingly guide the policies of lowincome and middle-income countries as well as development agencies, we are not aware of a critical analysis of how health research in Africa has evolved since the inception of the MDGs in 2000. ${ }^{6}$ We therefore conducted this bibliometric analysis to assess the profile and factors associated with health research publications in the WHO African Region since the onset of the new millennium.

\section{METHODS}

\section{Information sources and data collection process}

We used articles indexed in PubMed as a surrogate for total health research publications on the continent. We searched the database in November 2014. We generated publications originating from each country between 1 January 2000 and 31 October 2014 by selecting the 'advanced-search' option, followed by the 'publication date' field. We then searched the 'affiliation' field for each country, as shown in online supplementary appendix 1 . To accredit an article to countries, the method of 'absolute country counting' was adopted, in which each country contributing to an article received one paper credit based on the lead author's correspondence or reprint address. ${ }^{8}$ We included all papers indexed in PubMed with no disease, language or study design restrictions. In addition, we obtained data on country-level indicators (such as adult literacy rate, gross domestic product (GDP), expenditure on health, human development index, research and development expenditure and physicians per 100000 population) from World Bank data. ${ }^{9}$ One author (Olalekan Uthman) conducted the PubMed search and obtained country indicators from World Bank data.

\section{Trend analysis}

We examined time trends in health research productivity over the period from 2000 to 2014 using Poisson regression models with absolute health research output as an outcome variable and calendar year as a predictor. This method allows for estimation of time trends across individual calendar years to obtain average annual percentage change (AAPC), assuming that the rate of change is at a constant rate of the previous year. ${ }^{10}$ The Poisson regression procedure fits a model of the following form:

$$
\log \left(p b_{y}\right)=b_{0}+b_{1} y
$$

where pub is the number of articles per year, log is the natural $\log , \mathrm{b}_{0}$ the intercept, $\mathrm{b}_{1}$ the trend and $\mathrm{y}$ the year —year is given as $0,1,2, \ldots, 14$ (year 0 is 2000 , year 1 is 2001 and so on to 2014). The AAPC was calculated using the following formula:

$$
\mathrm{AAPC}=\left(\mathrm{e}^{\mathrm{b}_{1}}-1\right) \times 100
$$

It may not always be true to expect that a single AAPC can accurately characterise the trend in health research productivity over an entire 15-year period between 2000 and 2014. ${ }^{11}$ We therefore calculated the AAPC of the research output over 5-year periods: period 1 (2000-2004), period 2 (2005-2009) and period 3 (2010-2014).

We also calculated per cent relative growth and the per cent share of worldwide research output as follows:

Per cent relative growth $=$

$\left(\frac{\text { Number of articles in } 2014}{\text { Number of articles in 2014 - Number of articles in 2000 }}\right)$ $\times 100$

$$
\begin{aligned}
& \text { Per cent share of world research output ( per year) } \\
& =\left(\frac{\text { Number articles from all WHO Africa Region }}{\text { Total number of articles indexed in PubMed }}\right) \\
& \quad \times 100
\end{aligned}
$$

\section{Factors associated with health research productivity}

We used negative binomial regression models to explore the country-level factors associated with health research publications. We reported these associations as incidence rate ratios (IRRs) with their 95\% CI. We used negative binomial regression, a variant of the Poisson-based regression model for count data, because of statistically significant overdispersion (ie, greater variability in the number of indexed articles than might be expected). Negative binomial regression models have been shown to employ a more robust method to fit count data in the presence of overdispersion than the Poisson regression model itself. ${ }^{6}$ For regression analyses, the country-level factors were $\log$ transformed to normalise the data, as they were skewed. We processed and analysed data with Stata V.13 software (Stata Corp., College Station, Texas, USA) using two-sided tests, and defined statistical significance at the $5 \% \alpha$ level.

We did not publish a protocol for this study, which was conceived as a background paper for the 27th meeting of the African Advisory Committee on Health Research and Development held in Brazzaville Congo in January 2013.

\section{RESULTS}

Health research output pattern

We identified 107662 articles from countries in the WHO African Region indexed in PubMed between 2000 and 2014. Figure 1 shows the volume of publications per 


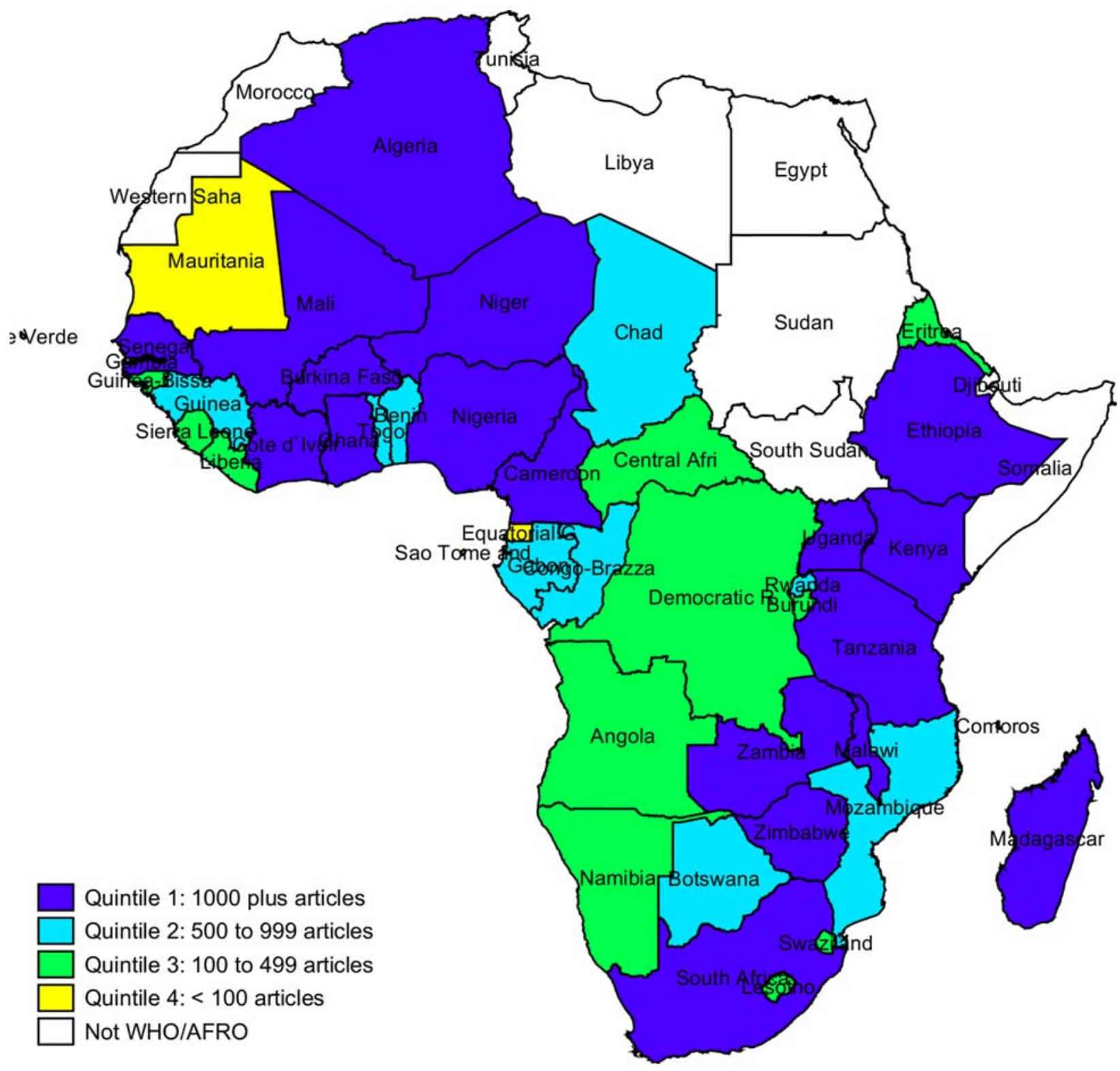

Figure 1 Map of health research in the WHO African Region indexed in PubMed from 2000 to 2014.

country broken down by quartiles. Eighteen countries occupy the highest quartile with more than 1000 articles each. Ten countries belong to the second quartile (ie, 500-999 articles) and 13 to the third quartile (100499 articles). Five countries with less than 100 articles each belong to the lowest quartile. The median number of articles per country was 727 (range 25-31 757). Table 1 shows the top-ranking countries in terms of relative contribution of each country to the total volume of articles and also the leading countries when health research publications are normalised by selected country-level variables. Authors from South Africa produced the highest number of articles ( $\mathrm{n}=31 \mathrm{757}, 29.5 \%)$, followed by Nigeria $(\mathrm{n}=17486,16.2 \%)$ and Kenya $(\mathrm{n}=6661,6.2 \%)$. Authors from these three countries combined produced 52\% of the total PubMed-indexed articles. The Gambia, Malawi and Guinea-Bissau had the highest number of publications after controlling for the country's GDP.

\section{Trend analysis}

Trends in health research publications from the WHO African Region are shown in figure 2. We observed a continuous increase in the number of articles indexed in PubMed with first authors from Africa. The number of articles increased from 3623 in 2000 to 12709 in 2014 (relative increase $251 \%$ ). Similarly, the per cent share of worldwide research output per year increased from $0.7 \%$ in 2000 to $1.3 \%$ in 2014 (figure 2). The trend analysis was also significant in confirming a continuous increase in health research publications from the African region. The productivity has been increasing from 2000 to 2014 by $10.3 \%$ per year $(95 \%$ CI $+10.1 \%$ to $+10.5 \%)$. However, the growth was most pronounced 
Table 1 Top 10 countries in the WHO African Region in terms of health research publications from 2000 to 2014, normalised by the indicated variable

\begin{tabular}{lllll}
\hline \multirow{2}{*}{ Rank } & Absolute number & Normalised by & & \\
\cline { 3 - 5 } 1 & Population & Gross domestic product & Total expenditure on health \\
2 & South Africa & South Africa & Gambia & South Africa \\
3 & Nigeria & Nigeria & Malawi & Nigeria \\
4 & Kenya & Kenya & Guinea-Bissau & Kenya \\
5 & Uganda & Uganda & Niger & Ethiopia \\
6 & Tanzania & Ethiopia & Zimbabwe & Tanzania \\
7 & Ethiopia & Tanzania & Uganda & Uganda \\
8 & Ghana & Ghana & Eritrea & Cameroon \\
9 & Cameroon & Cameroon & Kenya & Ghana \\
10 & Malawi & Senegal & Tanzania & Malawi \\
\hline
\end{tabular}

(steepest) between 2005 and 2009. The AAPC for the three periods were $+5.3 \%$ (95\% CI $+2.4 \%$ to $+6.3 \%)$ for period 1 (2000-2004), $+10.3 \% \quad(95 \%$ CI $+9.4 \%$ to $+11.1 \%)$ for period $2(2005-2009)$ and $+9.9 \%$ (95\% CI $+9.2 \%$ to $+10.5 \%)$ for period $3(2010-2014)$.

Factors associated with health research productivity

In univariable analyses, the country's GDP, physician density, total health expenditure, private health expenditure, research and development expenditure, and human development index had significant positive associations with increased health research publications (table 2). However, in the multivariable model, only the GDP maintained significant statistical association with the volume of health research publications. For every one $\log$ US $\$$ billion increase in national GDP, the total health research output increased by $105 \%$ (IRR $=2.05$, $95 \%$ CI 1.39 to $3.04, \mathrm{p}=0.0001)$. Increasing private expenditure on health also increased the total health research output; however, this statistical association was only marginally significant (IRR $=1.86,95 \%$ CI 1.00 to $3.47, \mathrm{p}=0.050$ ).

\section{DISCUSSION}

This study revealed that health research productivity in Africa is highly skewed, with three countries (South Africa, Nigeria and Kenya) contributing more than half of all research papers indexed in PubMed between 2000 and 2014. National GDP was an independent predictor of the volume of health research publications. Not unexpectedly, this study found that health research productivity varies widely across the WHO African Region, since the region is highly diverse and economic development and education levels vary widely between and even within countries. The findings corroborate those of previous bibliometric analyses that demonstrated that health research productivity worldwide is largely dependent on each country's GDP. ${ }^{12-21}$ It is important to note that although highly populous countries have correspondingly high levels of PubMedindexed publications, some smaller countries can be very productive when productivity is normalised with the number of inhabitants. ${ }^{15}{ }^{20-25}$ In addition to the country's GDP and population, we recognise that other factors such as the number of journals, high number of research institutions or universities, and research

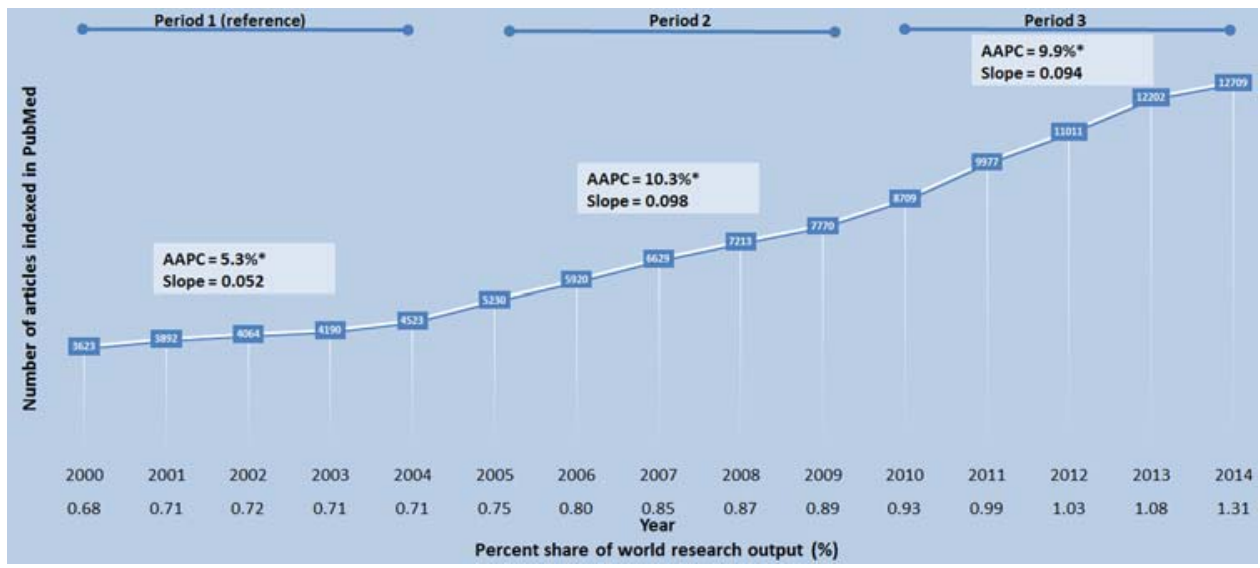

Figure 2 Trends in the WHO/AFRO health research article outputs indexed in PubMed (2000-2014; AAPC, average annual percentage change). *AAPC is significantly different from zero (0), $p=0.0001$. 
Table 2 Factors associated with health research publications in the WHO African Region from 2000 to 2014, identified by negative binomial regression

\begin{tabular}{|c|c|c|c|c|}
\hline \multirow[b]{2}{*}{ Variable } & \multicolumn{2}{|l|}{ Univariable } & \multicolumn{2}{|l|}{ Multivariable } \\
\hline & IRR (95\% CI) & p Value & IRR (95\% Cl) & p Value \\
\hline Gross domestic product (US\$) & 2.18 (1.86 to 2.54$)$ & 0.000 & 2.05 (1.39 to 3.04$)$ & 0.000 \\
\hline Adult literacy rate & $2.27(0.76$ to 6.85$)$ & 0.144 & $0.73(0.24$ to 2.18$)$ & 0.568 \\
\hline Physicians per 100000 population & 1.43 (1.06 to 1.94$)$ & 0.018 & $0.76(0.53$ to 1.09$)$ & 0.137 \\
\hline Total expenditure on health & 3.58 (1.10 to 11.63$)$ & 0.034 & $0.49(0.17$ to 1.41$)$ & 0.186 \\
\hline Private expenditure on health & 2.50 (1.36 to 4.62$)$ & 0.003 & 1.86 (1.00 to 3.47$)$ & 0.050 \\
\hline Research and development expenditure & 2.13 (1.79 to 2.54$)$ & 0.000 & $1.08(0.70$ to 1.68$)$ & 0.714 \\
\hline Human development index & 10.49 (1.87 to 58.94$)$ & 0.008 & $2.27(0.16$ to 31.71$)$ & 0.543 \\
\hline
\end{tabular}

specialisation may also have contributed to the observed high performance of the top three countries. Nachega et at previously found that 'in-country numbers of epidemiology or public health programmes' were an important and significant predictor of public health research productivity in Africa such that, for every one additional increase in the number of public health training institutions in an African country, research productivity increased by $241 \%$ (95\% CI $90 \%$ to $511 \%$ ).

The contributions of first authors from Africa to global health research production doubled between 2000 and 2014, yet remained minimal (ie, $0.7 \%$ in 2000 to $1.3 \%$ in 2014). ${ }^{13} 14181921{ }^{25-33}$ The difficulties in research, publication, editorial bias and information access facing Africa are profound and seem almost intractable. ${ }^{21} 29$ 34-39 Another difficulty facing African researchers is dissemination of findings to other parts of the world. $^{21}$ Most of the information published in African journals is largely not included in major databases. ${ }^{21} 2540$ Access to technological tools, information access and other equipment and supplies to ease research work is not always possible. ${ }^{21}$ In the 1990 s, the term '10/90 gap' was coined to express the acute global imbalance whereby low-income and middle-income countries experienced $90 \%$ of the world's major health problems, but received only $10 \%$ of its resources for health research. ${ }^{39} 41$

Although there is clearly a need for improving the performance of health researchers on the continent, African health decision makers should use the available research evidence to guide policy, strengthen practice and maximise the use of resources in order to improve the welfare of their citizens. ${ }^{2} 34243$ However, there appears to be a failure to apply available research evidence to improve the health of populations on the continent. ${ }^{7}$ This unfortunate situation may be related to the lack of sharing of research evidence for translation into policy and practice, a non-alignment of research conducted in African countries to national research policies and/or the non-existence of national health research policies with clearly defined priorities. ${ }^{44}$

The present research trajectory in Africa could experience healthier growth with definition of a coordinated, strong and up-to-date strategic plan for health research on the continent. Two years before the United Nations Millennium Declaration, the WHO Regional Office for Africa developed a 5-year (1999-2003) strategic health research plan with the major objectives being to support countries of the region to "develop a national health research strategy and the mechanisms needed to ensure adequate funding, effective coordination, and efficient management of research; develop their national capacity...to carry out health research relevant to major health needs and problems; and promote the use of research results to address major health issues and problems." ${ }^{3}$ Although we are not aware of a published critical assessment of the status of implementation of this strategic plan, currently available evidence indicates that institutions based in western countries drive the research agenda on the continent. ${ }^{6745}$ In the build-up to the 2008 Algiers conference on health research, ${ }^{42}$ the WHO Regional Office for Africa conducted a survey which revealed that health research priorities in one-third of African institutions are determined by agencies based outside the host country. In addition, the survey found that less than one-fifth of African countries had guidelines on development of collaborative agreements on health research involving institutions outside the country (unpublished WHO/AFRO data). Without such guidance documents, health research on the African continent will probably be influenced more by the demands of foreign institutions than by the health priorities of the host country.

Increasing the value of health research in Africa would require concrete evidence-informed actions to be taken by relevant authorities to ensure that health research is conspicuously present in both the pre- 2015 and post-2015 continental development agendas. The basic functions of an ideal national health research system in Africa should be stewardship, capacity building, funding, and generating and using research. ${ }^{43}$ Improved and harmonised public stewardship and funding commitment will be essential in sustaining present achievements and building a prosperous future research-for-health agenda in Africa. Such political commitment can best be achieved by defining, financing and monitoring a clear and considered plan for the continent's future health research enterprise. 
The latter should prioritise increasing the value of research on the continent by focusing on the continent's key health challenges as well as facilitating the uptake of the generated knowledge into policy and public health action. ${ }^{44}$ We see the WHO Regional Office for Africa and the African Union as leaders in coordinating and monitoring the African health research agenda.

It is no surprise that South Africa dominates the health research publications from the WHO African Region, because there is an increasing realisation of the need to promote indigenous health research in the country. ${ }^{46}$ Following the end of Apartheid in 1994, considerable policy-level steps were taken to reorient health research towards the needs of the vast majority of the population. These steps led to the publication of the Health Research Policy of 2001, whose aim was to develop a national health research system that contributes to equity in health development. ${ }^{46}$ This policy led to the implementation of a number of corrective interventions. In 2003, a new funding mechanism was established which entailed funding tertiary institutions based on their research outputs (ie, number of publications and number of postgraduate students produced). In terms of the National Health Act of 2003, a National Health Research Committee was established to advise the Minister of Health on health research priorities. The committee was tasked with defining and articulating a vision for the national health research system as well as identifying health research priorities through broad-based stakeholder (academia, industry and government) consultations. Through this work, the National Health Research Committee has highlighted the essential role of investment in health research to achieve a long and healthy life for South Africans, and has also identified seven priorities for the strengthening of the national system for health research. A national survey of research and development in 2008/ 2009 recorded gross domestic expenditure on research and development of 21 billion South African Rands for all research in South Africa, which was a nominal increase of 2.4 billion Rands from 18.6 billion Rands recorded for $2007 / 2008$. The $2008 / 2009$ expenditure represents a $13 \%$ nominal increase over that of $2007 / 2008{ }^{46}$

A bibliometric analysis of research outputs during the period 2000-2010 showed that these concerted interventions produced tangible results, ${ }^{46-49}$ with South Africa improving its worldwide ranking in the absolute number of research publications in all scientific fields by two positions to number 33 in the world in 2010. In health research publications, the country's relative share in world literature improved from $0.40 \%$ in $2000-2004$ to $0.60 \%$ in $2006-2010 .^{49}$ In 2008/2009, research expenditure in the health sciences was $14.8 \%$ of the total research and development expenditure (about $0.14 \%$ of GDP). South Africa aimed to spend 45 billion Rands on research and development and reach its target for gross expenditure on research and development of $1.5 \%$ of GDP by $2014 .^{46}$ It is a widely held view, however, that South Africa's health research system is severely underfunded from local sources. For example, the National Health Research Committee has estimated that the National Department of Health spent only $0.37 \%$ (416.5 million Rands) of its health budget (112.6 billion Rands) in health research in the 2010/2011 financial year, which falls far short of the recommendation of the health research policy of 2001 and subsequent undertakings at the Mexico Ministerial Forum on Research for Health $^{50}$ and the Global Ministerial Forum on Research for Health in Bamako ${ }^{51}$ to invest $2 \%$ of the health budget in health research. However, the National Department of Health has recognised the essential role of health research in achieving a long and healthy life for all South Africans through its 10 Point Plan of 20092014, which includes 'strengthening of research and development' as its 10 th priority. ${ }^{52}$ The National Health Research Committee acted on policy guidance of the National Department of Health by convening a National Health Research Summit in July 2011, which identified seven challenges and produced recommendations for the revitalisation of the health research system in South Africa. ${ }^{46}$ These efforts are expected to put South Africa on the highway towards research excellence.

Every research study has shortcomings, and ours was no exception to the rule. We sourced research publications only through PubMed, and only a single researcher extracted data. PubMed consists largely of Englishlanguage journals; therefore, it possibly contributes to selection bias because PubMed does not represent all the scientific and biomedical journals published. ${ }^{21}$ Although a sizeable proportion of research in Africa is undertaken by people affiliated to foreign institutions, we did not make an attempt to identify papers that report on research in Africa but do not have an explicit affiliation to an African institution. We did not explore this and other qualitative issues such as study type and quality because ours was essentially a quantitative study, and such qualitative assessments were beyond the scope of the study. Study quality is difficult to assess in a study like this, with large numbers of included studies and a mix of study designs. ${ }^{53}$ The cross-sectional nature of the data limits our ability to draw firm and causal inferences on the association between economic growth (country's GDP) and research productivity. It could be that economic growth leads to increased research productivity, or that enhanced research leads to economic growth. Despite the limitations, we believe that our study provides a good image of health research publications in the WHO African Region and has added value to the knowledge of health research productivity on the African continent. Further studies on research productivity in Africa should assess study type, quality and sources of funding.

\section{CONCLUSIONS}

There has been a significant improvement in health research in the WHO African Region since 2000, with 
some individual countries already having strong research profiles. However, optimal growth and efficiency of health research in the region will be realised more successfully if the way forward is mapped and monitored in a methodical and coordinated manner. In the meantime, countries of the region should implement WHO's Strategy on Research for Health: strengthening of the research culture (organisation); focusing research globally on priority health needs (priorities); helping to strengthen national systems for health research (capacity); promoting good practice in research (standards); and strengthening links between health research and health (translation).

\section{Author affiliations}

${ }^{1}$ Centre for Evidence-based Health Care, Faculty of Medicine and Health Sciences, Stellenbosch University, Cape Town, South Africa

${ }^{2}$ Warwick Centre for Applied Health Research and Delivery (WCAHRD), University of Warwick, Warwick Medical School, Coventry, UK

${ }^{3}$ South African Cochrane Centre, South African Medical Research Council, Cape Town, South Africa

${ }^{4}$ Research, Publications, and Library Services, WHO Regional Office for Africa, Brazzaville, Djoue-Brazzaville, Congo

${ }^{5}$ Division of Medical Microbiology \& Institute of Infectious Disease and Molecular Medicine, University of Cape Town, Cape Town, South Africa ${ }^{6}$ Department of Medicine, Groote Schuur Hospital \& University of Cape Town, Cape Town, South Africa

\section{Twitter Follow Charles Wiysonge at @CharlesShey}

Acknowledgements Professor Peter Martins Ndumbe, coauthor whose contributions appear below, died before submission of the manuscript to BMJ Open. He was a leading African scholar, and the authors dedicate this publication to his memory. They acknowledge Vesna Bjegovic-Mikanovic, Luis Gabriel Cuervo, Pablo Andrés Rodríguez Feria and Monica Valle Cristia for a critical review of an earlier version of this manuscript.

Contributors All authors participated in discussions about the data source and planning of the analyses, and critically revised successive versions of the paper. CSW and PMN conceived the study; CSW and OAU were involved in the search and selection of studies and data analysis; and CSW, OAU, MOO, MN, GDH, PMN and BMM were involved in the interpretation of results and drafting of the manuscript. CSW and OAU contributed equally to this work, and are joint first authors. CSW is the guarantor.

Funding This study was funded in part by the World Health Organization Regional Office for Africa. BMM is funded by the Lily and Ernst Hausmann Research Trust.

Competing interests $\mathrm{MOO}$ is a WHO employee and PMN was a WHO employee from the conception of this study to the time of his death in 2013.

Provenance and peer review Not commissioned; externally peer reviewed.

Data sharing statement No additional data are available.

Open Access This is an Open Access article distributed in accordance with the Creative Commons Attribution Non Commercial (CC BY-NC 4.0) license, which permits others to distribute, remix, adapt, build upon this work noncommercially, and license their derivative works on different terms, provided the original work is properly cited and the use is non-commercial. See: http:// creativecommons.org/licenses/by-nc/4.0/

\section{REFERENCES}

1. United Nations. The Millennium Development Goals Report 2013. Geneva, Switzerland: United Nations, 2013.

2. World Health Organization Regional Office for Africa. Atlas of health statistics of the African Region 2011. Brazzaville, Congo: AFRO, 2011.
3. World Health Organization Regional Office for Africa. Strategic health research plan, 1999-2003. Harare, Zimbabwe: AFRO, 1998.

4. Lewin S, Lavis JN, Oxman AD, et al. Supporting the delivery of cost-effective interventions in primary health-care systems in low-income and middle-income countries: an overview of systematic reviews. Lancet 2008;372:928-39.

5. Wiysonge CS, Lavis JN, Volmink J. Make the money work for health in sub-Saharan Africa. Lancet 2009;373:1174.

6. Nachega JB, Uthman OA, Ho YS, et al. Current status and future prospects of epidemiology and public health training and research in the WHO African region. Int J Epidemiol 2012;41:1829-46.

7. Wiysonge CS, Uthman OA, Ndumbe PM, et al. A bibliometric analysis of childhood immunisation research productivity in Africa since the onset of the Expanded Programme on Immunisation in 1974. BMC Med 2013;11:66.

8. Egghe L, Rousseau R, Van Hooydonk G. Methods for accrediting publications to authors or countries: consequences for evaluation studies. J Am Soc Info Sci 2000;51:145-57.

9. World Bank. The World Bank Data. 2012 [cited 11 November 2012].

10. Clegg LX, Hankey BF, Tiwari R, et al. Estimating average annual per cent change in trend analysis. Stat Med 2009;28:3670-82.

11. Fay MP, Tiwari RC, Feuer EJ, et al. Estimating average annual percent change for disease rates without assuming constant change. Biometrics 2006;62:847-54.

12. Cimmino MA, Maio T, Ugolini $\mathrm{D}$, et al. Trends in otolaryngology research during the period 1995-2000: a bibliometric approach. Otolaryngol Head Neck Surg 2005;132:295-302.

13. Falagas ME, Karavasiou AI, Bliziotis IA. Estimates of global research productivity in virology. J Med Virol 2005;76:229-3.

14. Falagas ME, Papastamataki PA, Bliziotis IA. A bibliometric analysis of research productivity in Parasitology by different world regions during a 9-year period (1995-2003). BMC Infect Dis 2006;6:56.

15. Hefler L, Tempfer C, Kainz C. Geography of biomedical publications in the European Union, 1990-98. Lancet 1999;353:1856.

16. Mela GS, Martinoli C, Poggi E, et al. Radiological research in Europe: a bibliometric study. Eur Radiol 2003;13:657-62.

17. Michalopoulos A, Falagas ME. A bibliometric analysis of global research production in respiratory medicine. Chest 2005;128:3993-8.

18. Rahman M, Fukui T. Biomedical research productivity: factors across the countries. Int J Technol Assess Health Care 2003;19:249-52.

19. Soteriades ES, Rosmarakis ES, Paraschakis K, et al. Research contribution of different world regions in the top 50 biomedical journals (1995-2002). FASEB J 2006;20:29-34.

20. Thompson DF. Geography of U.S. biomedical publications, 1990 to 1997. N Engl J Med 1999;340:817-18.

21. Uthman OA, Uthman MB. Geography of Africa biomedical publications: an analysis of 1996-2005 PubMed papers. Int $J$ Health Geogr 2007;6:46.

22. Benzer A, Pomaroli A, Hauffe $\mathrm{H}$, et al. Geographical analysis of medical publications in 1990. Lancet 1993;341:247.

23. Guardiola E. Geography of medical publication. Lancet 1993;341:634.

24. Rosselli D. Geography of biomedical publications. Lancet 1999;354:517.

25. Tijssen R. Africa's contribution to the worldwide research literature: new analytical perspectives, trends, and performance indicators. Scientometrics 2007;71:303-27.

26. Baltussen $\mathrm{A}$, Kindler $\mathrm{CH}$. Citation classics in critical care medicine. Intensive Care Med 2004;30:902-10.

27. Baltussen $\mathrm{A}$, Kindler $\mathrm{CH}$. Citation classics in anesthetic journals. Anesth Analg 2004;98:443-51.

28. Fenton JE, Roy D, Hughes JP, et al. A century of citation classics in otolaryngology-head and neck surgery journals. J Laryngol Otol 2002;116:494-8.

29. Keiser J, Utzinger J, Tanner M, et al. Representation of authors and editors from countries with different human development indexes in the leading literature on tropical medicine: survey of current evidence. BMJ 2004;328:1229-32.

30. Mahawar KK, Malviya A, Kumar G. Who publishes in leading general surgical journals? The divide between the developed and developing worlds. Asian J Surg 2006;29:140-4.

31. Paladugu R, Schein M, Gardezi S, et al. One hundred citation classics in general surgical journals. World J Surg 2002;26:1099-105.

32. Patel V, Kim YR. Contribution of low- and middle-income countries to research published in leading general psychiatry journals, 2002-2004. Br J Psychiatry 2007;190:77-8.

33. Tsai YL, Lee CC, Chen SC, et al. Top-cited articles in emergency medicine. Am J Emerg Med 2006;24:647-54. 
34. Horton R. North and South: bridging the information gap. Lancet 2000;355:2231-6.

35. Horton R. Medical journals: evidence of bias against the diseases of poverty. Lancet 2003;361:712-13.

36. Patel V, Sumathipala A. International representation in psychiatric literature: survey of six leading journals. $\mathrm{Br} J$ Psychiatry 2001:178:406-9.

37. Saxena S, Levav I, Maulik P, et al. How international are the editorial boards of leading psychiatry journals? Lancet 2003;361:609-10.

38. Tutarel $\mathrm{O}$. Composition of the editorial boards of leading medical education journals. BMC Med Res Methodol 2004;4:3.

39. Volmink J, Dare L. Addressing inequalities in research capacity in Africa. BMJ 2005;331:705-6.

40. Gaillard J. Use of publication lists to study scientific production and strategies of scientists in developing countries. Scientometrics 1992;23:57-73.

41. Davey S. The 10/90 Report on Health Research 2003-2004. Geneva, Switzerland: Global Forum for Health Research, 2004.

42. World Health Organization Regional Office for Africa. The algiers declaration: ministerial conference on research for health in the African region. Brazzaville, Congo: AFRO, 2009.

43. World Health Organization. The WHO strategy on research for health. Geneva, Switzerland: WHO, 2012.

44. Birbeck GL, Wiysonge CS, Mills EJ, et al. Global health: the importance of evidence-based medicine. BMC Med 2013;11:223.
45. Nwaka S, llunga TB, Da Silva JS, et al. Developing ANDI: a novel approach to health product R\&D in Africa. PLoS Med 2010;7: e1000293.

46. Senkubuge $F$, Mayosi BM. The state of the national health research system in South Africa. In: Padarath A, English R, eds. South African health review 2012/13. Durban: Health Systems Trust, 2013:141-50.

47. Pouris A. The writing on the wall of South African science: a scientometric assessment. S Afr J Sci 1996;92:267-71.

48. Pouris A. South Africa's research publication record: the last ten years. S Afr J Sci 2003;99:425-8.

49. Pouris A. Science in South Africa: the dawn of a renaissance? S Afr J Sci 2012;108:1-6.

50. World Health Organization. Mexico Ministerial Forum on Research for Health. Mexico City, Mexico-16-20 November 2004. 2004. http://www.who.int/rpc/summit/en/

51. World Health Organization. Global Ministerial Forum on Research for Health in Bamako. Bamako, Mali-17-19 November 2008. 2008 http://www.who.int/mediacentre/events/meetings/forum rh/en/

52. The South African health improvement plan. 2009. http://www. sarrahsouthafrica.org/LinkClick.aspx?fileticket=_cJl2FdD4-g\% 3D\&tabid=2067

53. Machingaidze S, Hussey GD, Wiysonge CS. Trends in the types and quality of childhood immunisations research output from Africa 1970-2010: mapping the evidence base. BMC Health Serv Res 2014;14:52. 